\title{
Updated distribution of the elusive Roach's mouse-tailed dormouse, Myomimus roachi Bate, 1937 (Mammalia: Rodentia: Gliridae) in Bulgaria
}

\author{
Nedko Nedyalkov ${ }^{1}$, Georgi Popgeorgiev², Anna Staneva ${ }^{3}$
}

1 National Museum of Natural History, Bulgarian Academy of Sciences, 1 Tsar Osvoboditel Blvd, 1000 Sofia, Bulgaria, nedko@nmnhs.com

2 National Museum of Natural History, Bulgarian Academy of Sciences, 1 Tsar Osvoboditel Blvd, 1000 Sofia, Bulgaria, georgi.popgeorgiev@gmail.com

3 BirdLife International, Cambridge, UK, staneva.anna@gmail.com

\begin{abstract}
Myomimus roachi is one of the rarest and least studied mammals of the Western Palearctic. It is rare and sparsely distributed in the Southeastern Balkans and Western Anatolia. After its initial finding in 1959, the species was recorded only sporadically. All available data for the species distribution in Bulgaria are summarised and three new country records are reported, which all together increases the number of squares on the $10 \times 10 \mathrm{~km}$ grid where the species has been recorded to 24 . The current species habitats and threats are discussed.
\end{abstract}

Keywords: Myomimus roachi, Bulgaria, distribution, threats, conservation

\section{Introduction}

In Europe, five species of dormice are found. The rarest, the Roach's mouse-tailed dormouse (Myomimus roachi), occurs only in the Southeastern Balkans and in several isolated localities in Western Anatolia. It is one of the rarest and least known mammal species in the Western Palearctic (Kryštufek, 2008). Peshev et al. (1960) reported the mouse-tailed dormouse as a new member for the European fauna under the name $M$. personatus subsp. $n$. on the base of several specimens caught in Southeastern Bulgaria. Thereafter the species was found in the neighbouring Turkish Thrace and along the Western Anatolian coastline (Mursaloğlu, 1973; Kurtunur, 1975). Unlike the rest of the European dormice, the mouse-tailed dormouse avoids forest habitats. It has been found in vineyards, on the edge of maize and cereal fields and in arable lands with sparse old trees (oak, peer and walnut trees; Peshev et al., 1960; Kryštufek \& Vohralík, 2005).

Bulgarian zoologists had caught the mouse-tailed dormouse predominantly on the ground surface (at that time snap traps were set only on the ground) and supposed that it was ground dwelling similar to its relative living in the Kopet Dag Mountain in Turkmenistan (Peshev et al., 1960). Later, in 1970s and 1980s in Turkish Thrace the species was captured mainly on trees (Kurtonur \& Özkan, 1990).

The Roach's mouse-tailed dormouse is a protected species (Annexes 2 and 3 of the Bulgarian Biological Diversity Act; VU in the Bulgarian Red Data Book (Popov, 2015); Annex 2 of Council Directive 92/43/ EEC or the Habitats Directive). The latest data for its distribution are summarised by Milchev \& Georgiev (2012). Its biology and ecology are still poorly studied and generally unknown, no specific research has been 


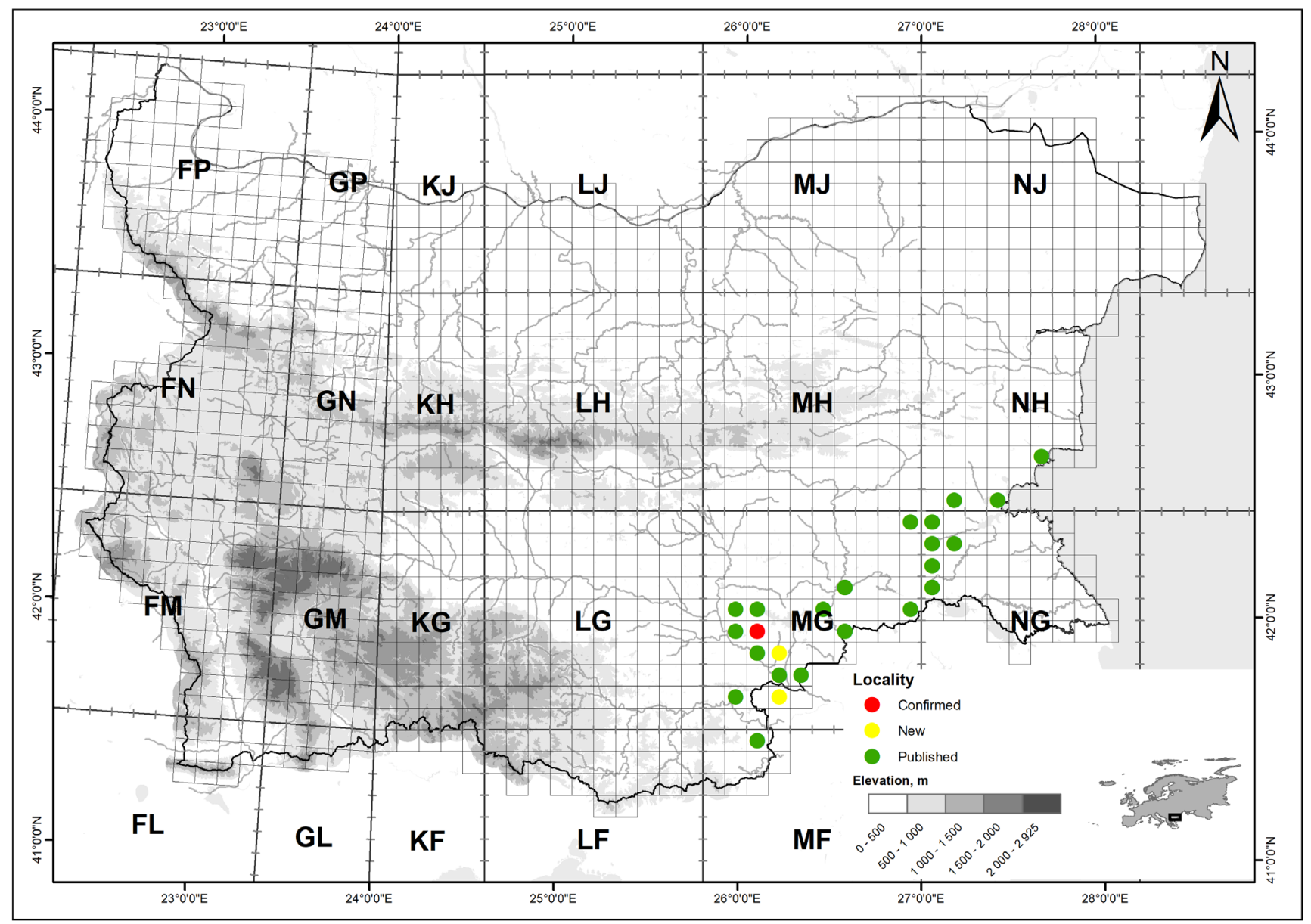

Fig. 1. Current distribution of Myomimus roachi in Bulgaria.

done on the species in Bulgaria. The species is occasionally recorded during faunistic surveys; the most recent records come from studies on the diet of owls. So far, 36 dormice have been caught and 20 have been found in the diet of owls.

\section{Material and methods}

The bulk of data were collected in 2011-2012 during the project for mapping species within Natura 2000 network. Within this project, all known locations until 2010 have been checked by live-trapping: Sherman and Longworth traps (baited with peanut butter, apple, sunflower seeds) were set in suitable habitats. Traps were set on the ground surface and on some old trees: oaks (Quercus sp.), walnut trees (Juglans regia) and pear trees (Pyrus communis) at a height of 1.5-2 m. About 2000 trap-nights were realised. As an addition- al method for species detection, pellets from the barn owl (Tyto alba) from 17 localities and the little owl (Athene noctua) from two localities were collected. Pellets were drained and after that carefully cleaned; bones, skulls and jaws were separated and used for determination of mammals. The minimum number of individuals (MNI) was identified by the maximum count of fragments identified from the left and right mandibula, the maxilla or separate teeth. A total of 21 species were identified from 4400 small mammals in the diet of Tyto alba and 13 in Athene noctua. Livetrapping was also done in the summers of 2016 and 2017.

The study area encompassed the territory of Southeastern Bulgaria and the species distribution is presented using squares of the $10 \times 10 \mathrm{~km}$ Military Grid Reference System grid (MGRS). We combined all previously unpublished observations and georeferenced published data into a GIS database, to update 


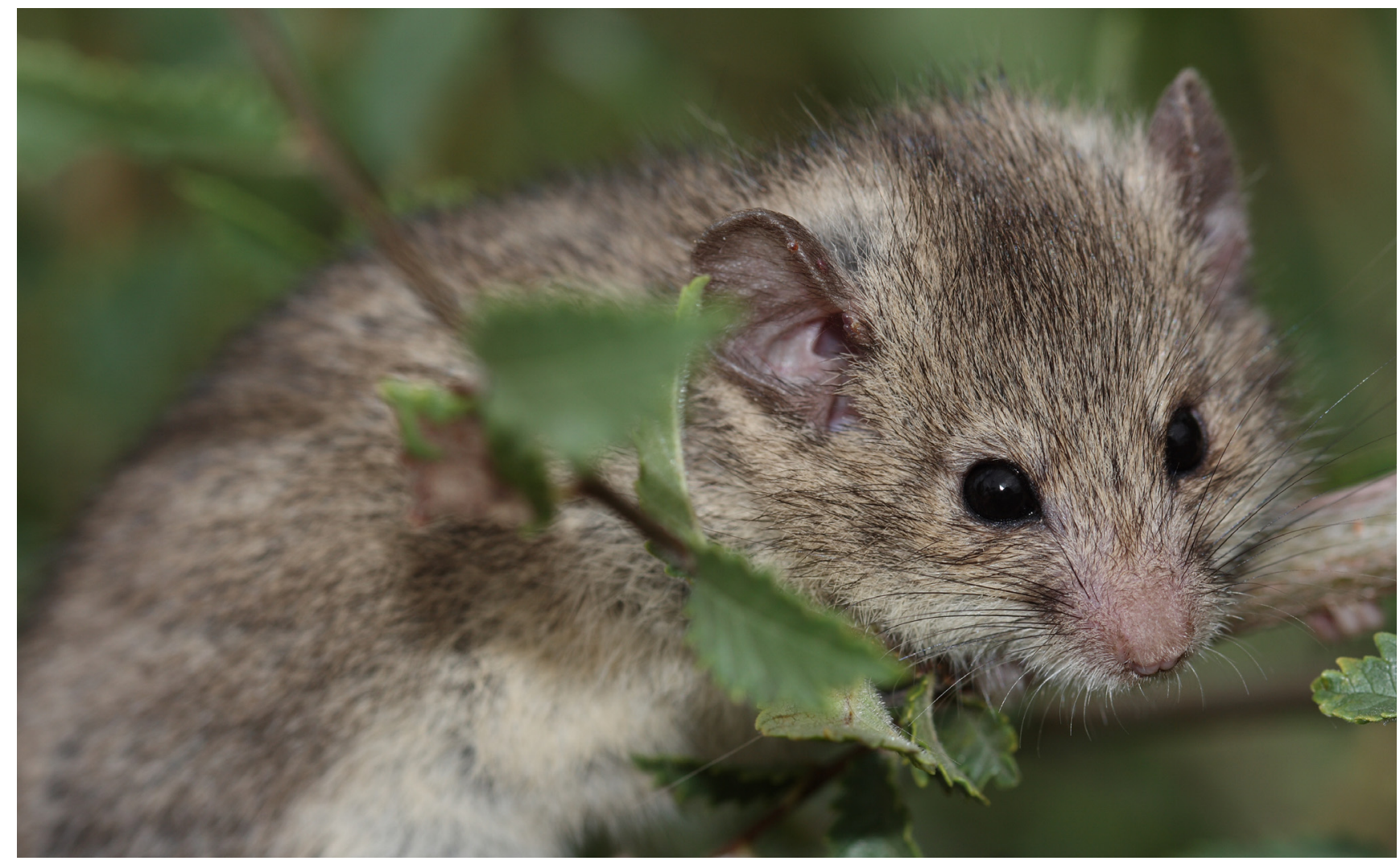

Fig. 2. Roach's mouse-tailed dormouse caught in 2017.

the current known distribution of the Roach's mousetailed dormouse.

\section{Results}

The species was not caught in traps during the 2011-2012 field seasons, despite the efforts (more than 2000 trap-nights). However, it was found in the barn owl pellets. Remains from $M$. roachi have been found in Generalovo and Izvorovo villages (Popov \& Nedyalkov, 2013). At both locations, M. roachi was presented by a single specimen found among 151 $(0.7 \%)$ and $356(0.3 \%)$ prey items of small mammals, respectively. The mouse-tailed dormouse represented a negligible part of the diet of T. alba $-0.045 \%$ (from 4400 prey items) in Southeastern Bulgaria, which was close to the previously reported proportions (Milchev \& Georgiev, 2012).

During faunistic surveys in 2017 in the region of the Sakar Mountain (MG33; Fig. 1) one adult female of $M$. roachi was caught by trapping on 6 May 2017. The specimen had the following measures (in $\mathrm{mm}$ ): body length -96 , tail -92 , ear height -10 , hind foot -21 and weight $-35 \mathrm{~g}$. After examination, the dormouse was released at the same point where it had been caught. The mouse-tailed dormouse was caught on an old (about 40-50 years old) oak tree (Quercus sp.) at $1.8 \mathrm{~m}$ height. The dominant habitat type in this locality was semi-open grassland with shrubs: blackthorn (Prunus spinosa), Jerusalem thorn (Paliurus spina-christi) and single trees or small forest patches of Quercus sp. (about 40-50 years old) and pear trees (Pyrus communis). This was the first catch of the species since 1978, when an adult mouse-tailed dormouse was caught around Burgas (Gorno Ezerovo Village, now part of the city), leg. Alexander Prostov. The specimen is stored and exhibited in the National Museum of Natural History at the Bulgarian Academy of Sciences, Sofia.

Our findings confirmed the presence of the species in the surroundings of Izvorovo Village, found previously from the region in the remains from the diet of the barn owl (materials of B. Milchev, in Peshev et al., 2004). We present two new localities where the species was recorded: Generalovo Village and MG33 in 


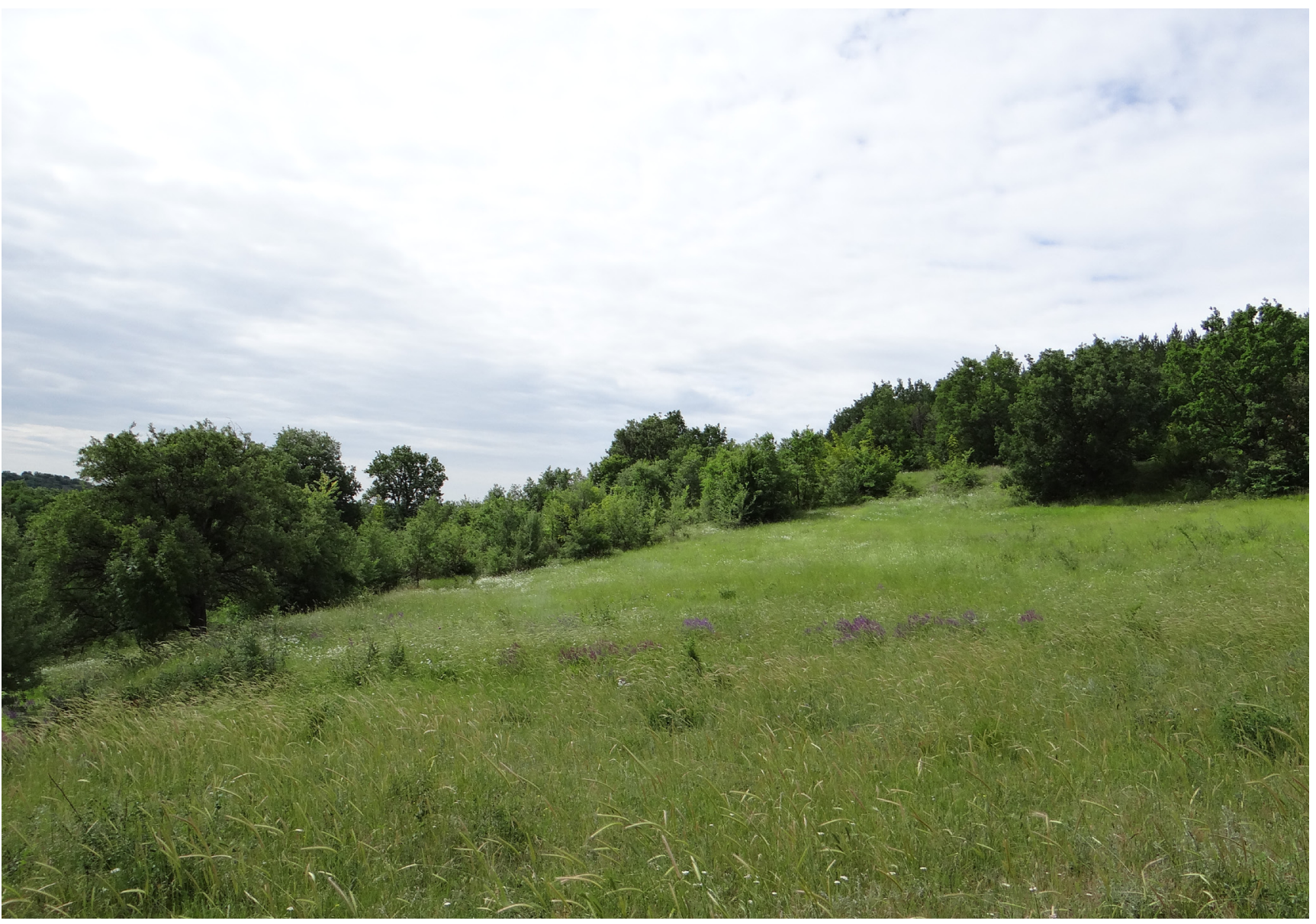

Fig. 3. Habitat of Myomimus roachi in the Sakar Mountain (UTM: MG33), SE Bulgaria.

the Sakar Mountain. The current species distribution is presented on Fig. 1 on the basis of our and previously published data (Heinrich, 1936; Peshev et al., 1960; Markov, 1964; Angermann, 1966; Peshev \& Angelova, 1967; Peshev \& Spassov, 1985; Peshev at al., 2004; Georgiev, 2004; Milchev \& Georgiev, 2012; Nedyalkov, 2013). Altogether, the species was found in 24 MGRS squares $(10 \times 10 \mathrm{~km})$ in Southeastern Bulgaria.

\section{Discussions}

Previous studies have reported that the species is ground-dwelling; it has been caught mainly on the ground surface and, thus, resembles its relative from the Kopet Dag Mountain - M. personatus, the only other known species at that time (Peshev et al., 1960). Habitats in Bulgaria are quite similar with these in Turkish Thrace (Kryštufek \& Vohralík, 2005).
Our data from radio-tracked survey on three mouse-tailed dormice (two female and one male), conducted in Turkish Thrace, have revealed that $M$. roachi spends much of its time on trees and lives in tree-holes and cavities at 1.5-2 $\mathrm{m}$ height, but also crosses wide open areas (150-200 m). It probably spends some time searching for fruits or insects (grasshoppers, crickets) on the ground (N. Nedyalkov, A. Staneva, personal data). In captivity, the species eats willingly insects and different fruits (Buruldağ \& Kurtonur, 2001).

The species habitat has been under anthropogenic pressure for a long time, mainly due to forestry activities: planting and replacing the native habitats - woods of mainly Quercus-Carpinus and the semi-open habitats with shrubs and trees, with alien or atypical species such as the black pine (Pinus nigra), black locust (Robinia pseudoacacia), Atlas cedar (Cedrus atlanti$c a)$. According to the national forestry database, there are multiple plantations at different stages (2-50 years 
old) within the range of $M$. roachi ( 886071.8 ha), with only the black pine covering $37.5 \%$ of this territory.

In the last few years, the species faces a new threat - a new practice for maintaining pastures has appeared in the region of Sakar Mountain and Dervent hills. In order to get subsidies for open pastures, the farmers use heavy-duty shredders to completely remove shrubs and trees. This practice not only changes the habitats through removing the hedgerows and fruit trees, but directly kills and exposes for future depredation other animals, such as tortoises (Testudo sp.), hedgehogs (Erinaceus roumanicus), hares (Lepus europaeus). In addition, fires are common events during the autumn drought and every year they destroy big part from the suitable for the dormouse habitats.

Haas (1959) suggested that the mouse-tailed dormouse has vanished from the Middle East in the near past because of habitat changes - loss of fruit trees (Zizyphus sp.) as a result of intensive human cultivation. The species was quite common and used to be the predominant glirid during the Middle and Late Pleistocene but disappeared suddenly during the Late Bronze Age (Tchernov, 1975).

According to the last mapping project conducted in Bulgaria, the mouse-tailed dormouse is listed for 21 sites from Natura 2000 network, but still $50 \%$ from the known records lie outside the frame of Natura 2000. Its national population is estimated at 2226 adult individuals (Popov \& Nedyalkov, 2013), but one should take it with a grain of salt. This estimation is made based on scarce population data and suitable habitats.

Bulgaria is the only country in the EU responsible to protect this species, but still not a single active conservation or monitoring project on the species has been launched. A big gap exists in our knowledge (for its biology and ecology) about this species, compared to the rest of the European dormice. There is need for urgent conservation efforts preventing further habitat degradation. A monitoring scheme should be launched as soon as possible.

\section{Acknowledgments}

The field survey in 2011-2012 was realised within a project for mapping species and habitats in the frame of Natura 2000 network. The field survey in 20162017 was supported by the project "Restoration and sustainable management of the imperial eagle's for- aging habitats in key Natura 2000 sites in Bulgaria" (LIFE14 NAT/BG/001119) conducted by the Bulgarian Society for the Protection of Birds.

We thank Nikolay Tzankov, Dimitar Plachiyski and Yordan Koshev for their help and company during the fieldwork. Yurii Kornilev checked and improved our English.

This work would not be possible without Ebru and Halim Diker, who shared with us (NN, AN) their experience with Myomimus roachi.

We acknowledge the referees who provided valuable comments on an earlier draft.

\section{References}

Angermann R. 1966 Ein weiterer Fundort von Myomimus personatus Ognev, 1924. Zeitschrift für Säugetierkunde 31: 411.

Buruldağ E., Kurtonur C. 2001 Hibernation and postnatal development of the mouse-tailed dormouse, Myomimus roachi reared outdoor's in a cage. Trakya University Journal of Scientific Research, Ser. B, 2 (2): 179-186.

Georgiev D. 2004 Conservation status of the small mammals (Mammalia: Insectivora, Lagomorpha, Rodentia) in Sakar Mountain (South-eastern Bulgaria). Travaux scientifiques Université de Plovdiv "Paisii Hilendarski", Biologie, Animalia 40 (6): 153-164.

Haas G. 1959 Some remarks on Philistomys roachi Bate. Journal of Natural History, Series 13, 2 (23): 688-690.

Heinrich G. 1936 Über die von mir in Jahre 1935 in Bulgarien gesammelten Säugetiere. Mitteilungen aus den Königlichen naturwissenschaftlichen Instituten in Sofia - Bulgarien 9: 33-48.

Kryštufek B. 2008 Myomimus roachi. The IUCN Red List of Threatened Species 2008: T14087A4389146. http://dx.doi.org/10.2305/ IUCN.UK.2008.RLTS.T14087A4389146.en. Last accessed 2 January 2018.

Kryštufek B., Vohralík V. 2005 Mammals of Turkey and Cyprus. Rodentia I: Sciuridae, Dipodidae, Gliridae, Arvicolinae. Annales Majora, Koper, 292 pp.

Kurtonur C. 1975 New records of Thracian mammals. Säugetierkundliche Mitteilungen 23: 14-16.

Kurtonur C., Özkan B. 1990 New records of Myomimus roachi (Bate 1937) from Turkish Thrace 
(Mammalia: Rodentia: Glirdae). Senckenbergiana Biologica 71 (4): 239-244.

Markov G. 1964 Insektenfressende Säugetiere und Nagetiere in Thrakien (Südbulgarien). In Paspalev G. (ed.) Die Fauna Thrakiens (Sammelwerk). Band I. Verlag der Bulgarischen Akademie der Wissenschaften, Sofia, 19-53 (In Bulgarian).

Milchev B., Georgiev V. 2012 Roach's mouse-tailed dormouse Myomimus roachi distribution and conservation in Bulgaria. Hystrix, the Italian Journal of Mammalogy 23 (2): 67-71.

Mursaloğlu B. 1973 New records for Turkish rodents (Mammalia). Communications de la Faculté des Sciences de l'Université d'Ankara, Ser. C, 17: 213-219.

Nedyalkov N. 2013 New records of some rare rodents (Mammalia: Rodentia) from South-East Bulgaria. ZooNotes 39: 1-4.

Peshev Ts., Dinev T., Angelova V. 1960 Myomimus personatus Ogn. (Myoxidae) - a new species of rodent to the fauna of Europe. Bulletin de l'Institut zoologique de l'Académie des sciences de Bulgarie 9: 305-313. (In Bulgarian).

Peshev Ts., Angelova V. 1967 Insectivora and Rodentia in southern parts of Bulgaria. Annuaire de 1'Université de Sofia, Faculté de Biologie 61 (1): 89-98. (In Bulgarian).
Peshev Ts., Spassov N. 1985 Bulgarian mouse-tailed dormouse, Myomimus roachi bulgaricus Rossolimo, 1976. In: Botev B., Peshev Tz. (eds) Red Data Book of the People's Republic of Bulgaria. Volume 2. Animals. Publishing House of the Bulgarian Academy of Sciences, Sofia, 140-141. (In Bulgarian).

Peshev Ts., Peshev D., Popov V. 2004 Fauna bulgarica. 27. Mammalia. Editio academica, Sofia. (In Bulgarian).

Popov V. 2015 Mouse-tailed dormouse, Myomimus roachi (Bate, 1937). In: Golemansky V. (ed.). Red Data Book of the Republic of Bulgaria. Volume 2. Animals. Bulgarian Academy of Sciences, Ministry of Environment and Waters of Bulgaria, Sofia, p. 233.

Popov V., Nedyalkov N. 2013 The mouse-tailed dormouse (Myomimus roachi) - general report. Natura 2000, Bulgaria, 32 pp. (In Bulgarian) http:// natura2000.moew. government.bg/PublicDownloads/Auto/SDF_REF_SPECIES/2617/2617 Species 102.zip. Last accessed 29 June 2018.

Tchernov E. 1975 Rodent faunas and environmental changes in the Pleistocene of Israel. In: Prakash I., Ghosh D.K. (eds) Rodents in desert environments, Springer, Netherlands, 331-362. 